\title{
DE EVA ÀS DAMAS DE CHRISTINE DE PIZAN: DESCONSTRUINDO A IMAGEM DA MULHER NA IDADE MÉDIA*
}

\author{
FROM EVE TO THE LADIES OF CHRISTINE DE PIZAN: \\ DECONSTRUCTING THE IMAGE OF WOMEN IN THE MIDDLE AGES
}

\author{
Pedro Carlos Louzada FONSECA**
}

\begin{abstract}
Resumo: A tendência unidirecional da historiografia tradicional no tratamento de seus objetos de estudo acarreta certa inviabilização na investigação das relações de gênero nos estudos medievais, principalmente na sua articulação com o literário. A orientação sistêmica desse modelo historiográfico, fundamentada em prerrogativas da chamada colonialidade de gênero com a sua inarredável cosmovisão androcêntrica, mostrase desde sempre constituída de formações mentais e retóricas construídas e perpetuadas pela força da sua origem e tradição. Com a intenção de investigar/desconstruir alguns aspectos da construção da realidade feminina no âmbito de configurações ideológicas e politicamente apresentadas na Idade Média que Jacques Le Goff chama "longa" (2008), este artigo examina a questão do tornar-se mulher em autores e obras da Idade Média. Para tanto, procede a um significativo resgate antológico de textos medievais de fundamental importância para o tratamento desse complexo e polêmico tema da história e cultura medievais. No decorrer desse exame crítico-desconstrutor, cobrindo o intervalo compreendido de Eva às damas de Le Livre de la Cité des Dames de Christine de Pizan, deverão surgir realçados traços e fundamentos da misoginia medieval na sua relação com a invenção do amor romântico discutida por Howard Bloch (1995), um dos mais interessantes fenômenos da história do pensamento e da cultura Ocidental.
\end{abstract}

Palavras-chave: Literatura Medieval. Mulher. Imagem. Desconstrução. Christine de Pizan.

Abstract: The unidirectional tendency of traditional historiography in the treatment of its objects of study leads to a certain impossibility in the investigation of gender relations in medieval studies, mainly in its articulation with the literary. The systemic orientation of this historiographical model, based on prerogatives of the so-called gender coloniality with its unrivaled androcentric worldview, has always been constituted of mental and rhetorical formations built and perpetuated by the strength of its origin and tradition. Intending to investigate/deconstruct some aspects of the construction of the feminine reality within the scope of ideological and politically presented configurations in the Middle Ages, named "long" by Jacques Le Goff (2008), this paper examines the issue of becoming woman in authors and works of the Middle Ages. To this end, it proceeds to a significant anthological rescue of medieval texts of fundamental importance for the

\footnotetext{
* Duas publicações anteriores sobre aspectos temáticos trazidos à discussão por Christine de Pizan acerca da sua crítica no Le Livre de la Cité des Dames sobre a derrogação da imagem feminina foram analisados pelo autor do presente artigo. A primeira delas, intitulada "Christine de Pizan e a releitura da misoginia medieval de Le Livré de la Cité des Dames" foi feita nos Anais Eletrônicos do IX Encontro Internacional de Estudos Medievais da ABREM (UFMT, 2011, p. 55-561). A segunda, intitulada Christine de Pizan e Le Livre de La Cité des Dames: ponto de releitura da visão tradicional da mulher, foi realizada na Revista Cerrados (UnB, vol. 20, n. 32, 2011, p. 299-320). Em ambas as publicações, o autor analisou o processo de dialogia intertextual de Christine de Pizan com os textos antifemininos da sua tradição literária. No presente artigo o autor, fundamentado em conclusões anteriores, examina a figura feminina desde o seu projeto genésico de Eva até as damas de Christine de Pizan que apresenta, por assim dizer, um terminus ao projeto misógino da auctoritas medieval sobre a questão das relações de gênero, ao mesmo tempo que acena para a possibilidade de uma história interna de um gênero literário dessas relações misóginas.

** Doutorado em Romance Languages and Literatures pela University of New Mexico (Estados Unidos, 1990); Professor Titular da Universidade Federal de Goiás (UFG, Brasil). E-mail: pfonseca@globo.com. ORCID iD: https://orcid.org/0000-0003-0213-7855.
} 
treatment of this complex and controversial subject of medieval history and culture. In the course of this critical-deconstructive examination, covering the range from Eve to the ladies of Christine de Pizan's Le Livre de la Cité des Dames, the study analyzes some of the traces and foundations of the medieval misogyny in its relationship with Howard Bloch's romantic love, one of most interesting phenomena in the history of Western thought and culture.

Keywords: Medieval Literature. Woman. Image. Deconstruction. Christine de Pizan.

Indubitavelmente reverberado na formação da visão acerca da realidade feminina desde os primórdios do cristianismo, o apócrifo Evangelho de São Tomé comenta, no seu versículo 114, que

Simão Pedro disse: Seja Maria afastada de nós, porque as mulheres não são dignas da vida. Respondeu Jesus: Eis que eu a atrairei, para que ela se torne homem, de modo que também ela venha a ser um espírito vivente, semelhante a vós homens. Porque toda a mulher que se fizer homem entrará no Reino dos Céus.

A força desse dito de Jesus, apesar de sua negada canonicidade, passada a perplexidade diante de uma inusitada proposta de entendimento, teve, entretanto, sua naturalização efetivada por meio de uma das mais surpreendentes metáforas cunhadas pela estilística misógina da Idade Média, isto é, a mulher é homem no plano da salvação divina. No contexto das formulações adivinhadoras do discurso religioso medieval, essa prescrição de a mulher se virilizar para entrar no Reino dos Céus não é, entretanto, de tão única surpresa, aparecendo registrada por uma ampla tradição literária de textos que abordam essa problemática de transfiguração simbólica na cristandade medieval.

Cerca de aproximadamente dois milênios depois desse pronunciamento de alto teor misógino acerca da construção do feminino no pensamento medieval, foi exatamente uma mulher, Simone de Beauvoir, que se encarregou de fazer, até então, um dos mais consequentes balanços críticos da visão misógina das mulheres na perspectiva das coordenadas da tradição religiosa:

Com São Paulo firma-se a tradição judaico-cristã ferozmente antifeminista. São Paulo exige das mulheres discrição e modéstia; baseia-se, no Antigo e Novo Testamentos, o princípio da subordinação da mulher ao homem. "O homem não foi tirado da mulher e sim esta para o homem". E alhures: "Assim como a Igreja é submetida por Cristo, em todas as coisas submetem-se as mulheres a seus maridos". Numa religião em que a carne é maldita, a mulher se apresenta como a mais temível tentação do demônio. Tertuliano escreve: "Mulher, és a porta do diabo. Persuadiste aquele que o diabo não ousava atacar de frente. É por tua causa que o filho de Deus teve que morrer, deverias andar sempre vestida de luto e de andrajos". E Santo Ambrósio: "Adão foi induzido ao pecado por Eva e não Eva por Adão. É justo que a mulher aceite como soberano aquele que ela conduziu ao pecado". São Tomás será fiel a essa tradição ao declarar que a mulher é um ser 
"ocasional" e incompleto, uma espécie de homem falhado. "O homem é a cabeça da mulher, assim como Cristo é a cabeça do homem", escreve. "É indubitável que a mulher se destina a viver sob o domínio do homem e não tem por si mesma nenhuma autoridade" (BEAUVOIR, 1980, p. 118-119).

Se, nesse momento de sua reflexão, Beauvoir não aborda de forma mais taxativa a questão desse tipo de "masculinização" da mulher no discurso misógino da Idade Média, tornam-se, entretanto, nela subliminarmente inferidos aspectos desse processo prescritivo e preconceituoso da desmoralizada realidade feminina a partir da tradição hebraica e cristã. Ainda a percuciente reflexão de Beauvoir traz os elementos básicos da construção não de mulheres historicamente verificadas, mas sim da abstração de uma realidade feminina que se efetua justamente para servir a estratégias ideológicas reducionistas e essencialistas de um discurso masculinista que coloniza o objeto de seu interesse.

Apesar de ser motivo de controvérsia a consideração de que a misoginia medieval possa não ter uma história literária interna, tão ao gosto dos estudos das historiografias tradicionais que se batem por uma visão evolucionista herdeira de hegemonias disciplinares arcaicas, pode-se, entretanto, fazer um estudo antológico de textos medievais alinhados nas diversas características dimensionais dos tempos e modos das realidades femininas a partir da tradição bíblica. E, nesse estudo antológico, a pertinência daquela reflexão anteriormente colocada acerca do reducionismo essencialista da misoginia na tradição literária medieval poderia, inclusive, ser comprovada. Reducionismo esse que se apresenta fundado em prerrogativas de verdade histórica sub specie aeternitatis construídas sob a égide de um antigo patriarcalismo escriptocêntrico que da tradição hebraica se atualizou na sua formação ocidental, ou seja, na construção do cristianismo.

Consoante a esse direcionamento reflexivo, o que se verá a seguir neste estudo sobre a desconstrução da imagem da mulher formada no período medieval será uma abordagem crítica de significativos pronunciamentos de autores e obras da Idade Média conferidos no cenário misógino da tradição medieval a partir dos apontamentos presentes no comentário de Simone de Beauvoir anteriormente citado. Apesar de esse comentário se restringir à visão apostólica e patrística acerca da natureza e caráter da mulher, no entanto, ele oferece elementos básicos que, a partir dos escritos dos primeiros séculos dos chamados Padres da Igreja, foram glosados por seus seguidores de formação religiosa ou mesmo secular, culminando essa disseminação nas adaptações vernáculas da tardia Idade Média. 
Consideradas essas condições, não é por acaso que Simone de Beauvoir estabelece, com a lembrança da atuação apostólica e teológica de São Paulo, a tradição judaico-cristã "ferozmente antifeminista," haja vista o fato bastante considerado de ele se apresentar como um nome emblemático dos primórdios da história da misoginia medieval. Nesse sentido, acerta Simone de Beauvoir ao eleger a figura do santo como fiel apoiador e divulgador das palavras de Simão Pedro lembrado por São Tomé nas suas considerações cristológicas acerca do mandamento de subordinação da mulher ao homem. Mandamento esse passível de ser considerado texto inaugural do pensamento misógino medieval acerca do discurso das relações de gênero.

A crítica 'protofeminista' de Simone de Beauvoir principia a sua referência ao assunto apontando duas características basilares exigidas estarem presentes no caráter da mulher, ${ }^{1}$ quais sejam, a sua a discrição e modéstia, exatamente as falhas que a responsabilizaram transgressora do mandamento divino e instaladora do pecado desde a sua criação no Paraíso. Eva havia falhado por desobediência e voluntariedade, atributos situados na contramão da obediência modesta e discreta recomendada por Deus para usufruto do homem das benesses do Paraíso.

Mutatis mutandis, esse mesmo tópos bíblico da obediência edênica encontra-se glosado ad nauseam na literatura medieval, merecendo ser lembrado, para princípio de discussão e devido ao peso de sua idoneidade de auctoritas, nos representantes da patrística e do seu legado medieval, desde Santo Ambrósio, passando por São Jerônimo, Santo Agostinho e Graciano, entre tantos outros, para se ficar aqui só no âmbito da literatura religiosa. Todavia, um possível terminus para essa consideração temática, fazendo-lhe justiça comparativa, poderia ser encontrado na figura, de não menos competência na questão de autoridade, de São Tomás de Aquino.

Um estudo exegético do sentido e significado da transgressão primordial de Eva em relação ao seu companheiro Adão a coloca como a primeira culpada da introdução do pecado no mundo, justamente por ter sido criada nas condições de sua definição de mulher. Eva é o primeiro caso de indiciamento no discurso bíblico da noção de predestinação prefigurada. A sua imagem é o negativo do futuro retrato da Virgem Maria, assim como Adão prefigura a imagem do próprio Cristo. Por esse rápido cruzamento exegético pode-se já de antemão considerar que o teor misógino da Escritura Sagrada se faz presente já no Gênese, na criação da mãe da humanidade.

\footnotetext{
${ }^{1}$ A realidade feminina na perspectiva da crítica contemporânea pluraliza esse conceito e emprega o termo "mulheres" baseada no ponto de vista da multidimensionalidade histórica. Entretanto o emprego, neste estudo, do termo "mulher" no singular é proposital para a fidelidade foco-problemática da referência crítica ao emprego de práticas essencialistas da tradicional visão cultural acerca das mulheres.
} 
É bastante intrincada a formação, no decorrer da Idade Média, da rede pecadológica derivada dessa primeira transgressão. Uma das mais lembradas reflexões lógicas desse engendramento transgressivo reside exatamente no estabelecimento do entendimento de quem falha primeiro merece ser secundário e subalterno na ordem natural das coisas, da mesma forma que quem nasce primeiro merece o primeiro lugar, conforme entende a lei primogênita. Desse modo, num sentido tautológico, a secundária posição de Eva já estaria prefigurada no tempo e modo secundários da sua própria criação, condição essa que se comprova com o seu pecado.

$\mathrm{Na}$ verdade, as exigências das virtudes paulinas requeridas para o comportamento moral e religioso da mulher coadunam-se com prédicas da moral religiosa substanciadas no Antigo e Novo Testamentos a respeito da questão da assimetria de poder nas relações de gênero, em que a mulher é sempre subalterna ao homem, devendo-lhe obediência e servidão. Nesse sentido, reforça São Paulo quando comenta que "Com efeito, o homem não foi tirado da mulher, mas a mulher do homem; nem foi o homem criado para a mulher, mas sim a mulher para o homem" (Coríntios 1. 11: 8-9). O apóstolo, recorrendo-se ao método analógico característico da epistemologia medieval para o conhecimento das coisas, naturalizando a submissão feminina à inevitabilidade teocêntrica da religião cristã, segue dizendo que "Assim como a Igreja é submetida por Cristo, em todas as coisas submetem-se as mulheres a seus maridos" (Efésios 5: 24).

Simone de Beauvoir traça um círculo hermenêutico entre a prescrita submissão conjugal da mulher por ter pecado primeiro e induzido o homem a pecar e a primazia nela do comando da carne fraca. Essa questão da carnalidade feminina, entretanto, tem as suas origens no que se pode considerar como raízes aristotélicas da misoginia medieval. Para Aristóteles (384 - 322 a.C.), em De generatione animalium (On Generation of Animals / Geração dos animais) e seu seguidor Galeno (131 - 201), em De usu partium corpori humani (On the Usefulnes of the Partes of the Body / Sobre a utilidade das partes do corpo) fica claro que as fêmeas possuem uma natureza inferior, de menor completude anímica compara à dos machos (ARISTOTLE, 1963, 726b, 727a, 727b, 729a, 737a, 738b, 775a, p. 91-93, 97, 101-103, 109, 173-175, 185, 459-461; GALEN, 1968, ii, p. 630-632) ${ }^{2}$, fato que os levou a considerar o corpo feminino como de qualidade inferior ao

\footnotetext{
${ }^{2}$ Dois esclarecimentos de caráter técnico-metodológico merecem ser especialmente feitos aqui. O primeiro deles tratase da consideração dada neste estudo aos nomes próprios que aparecem nos textos dos autores estudados. Relativamente a eles, procurou-se manter a grafia do nome da forma como aparece na fonte utilizada, quando se tratou de nomes de referência secundária. Para os nomes de importância e referência mais destacada, buscou-se a sua ortografia em português, de preferência a de uso mais adotado. O segundo deles refere-se à sistemática da referência
} 
masculino considerado perfeito em suas eficazes propriedades gerativas e mentais (ROUSSELLE, 1988, p. 12-20; JACQUART; THOMASSET, 1988, p. 55-56).

Essa ideia de a fêmea ser por princípio mais concernente à matéria a buscar a forma de regência masculina entra na tradição judaico-cristã da Idade Média casando-se perfeitamente com a narração da criação de Adão e Eva. A partir daí, fica aproveitada pela mentalidade misógina dessa tradição um entendimento de que a mulher, não tendo sido criada no momento da criação original do mundo, não seria à semelhança direta com a imagem divina, mas sim à semelhança do homem, o provedor da matéria da sua criação. Estava inaugurada aqui, a partir desse ponto, uma verdadeira história peregrina do conhecido tópos da costela de Adão, apanágio de inúmeros debates surgidos para a difamação e defesa da mulher na Idade Média.

Essa arcana configuração da mulher como produto carnal derivado encontra respaldo ideológico em vários momentos do pensamento medieval, nos quais se tornam claras formulações que associam a carnalidade como maldição em constante derrapagem para o terreno do demoníaco intermediada $a b$ origine pela susceptibilidade da natureza feminina ao mal. Dentre os vários momentos pronunciados acerca desse assunto, merecem ser citados o que sobre ele coloca Tertuliano (155 - 222), em De culto feminarum (The Apparel of Women / Toalete das mulheres) acerca da luxúria provocada pela toalete e indumentária femininas.

Tertuliano, lutando contra o paganismo das vestes e ornamentação ainda presente nas mulheres recém-convertidas em desfavor da espiritualidade ascética propugnada pelo cristianismo primitivo, torna-se num arauto do processo de demonização da mulher cuja exacerbação verificase no final da Idade Média e princípios dos tempos modernos (FONSECA, 2020, p. 65-74; BEAUVOIR, 1980, p. 118-119).

Entretanto, esse curto-circuito da redução da mulher ao sensório e material em correspondência com a maldição da carne iniciada no entendimento da própria criação bíblica do homem, já comparece problematizado desde os primórdios da patrística. É na esteira dessas ideias que Santo Ambrósio (c. 339 - 397), em De Paradiso (Paradise / Paraíso) (c. 375), propõe uma interessante alegoria para a Queda de Adão e Eva, na qual a mulher representa os sentidos do corpo

parentética da localização de passagens ou citações das fontes consultadas. Nesse particular optou-se pelo método tecnicamente aceito para citações de obras clássicas de apenas indicar, conforme o caso, o livro, capítulo, seção, ou demais segmentos, em que a passagem e a citação se encontram. 
e o homem, a mente. Completa o santo dizendo que os prazeres agitam os sentidos, os quais, por sua vez, afetam a mente (AMBROSE, 1961, XV. 73, 351).

Santo Agostinho (c. 354 - 430), um dos pilares da cristandade, apenas aparentemente não discriminou o lamentável estado corpóreo da mulher, ao seguir o ensinamento de Galateus 3: 2628 acerca da equivalência teológica dos dois sexos. Mesmo assim - e não concordando, em $D e$ Trinitate (The Trinity / Trindade) (AUGUSTINE, 1963), com o equacionamento da mulher ao corporal - considera, como perturbadora da serenidade e da espiritualidade da mente masculina, a instigante predisposição feminina para as solicitudes materiais e sensoriais (BORRESEN, 1981, p. 25-30).

É no âmbito das suas considerações acerca dessa predisposição da mulher para os apetites da carne que, finalmente, o bispo de Hipona oferece uma reflexão sobre o sentido literal da Queda. Em De Genesi ad litteram (The Literal Meaning of Genesis / O sentido literal de Gênesis), Santo Agostinho arrazoa sobre a superioridade do espírito mental do homem em detrimento da inferioridade e da prevalência do espírito carnal da mulher que, desdotando-a para o entendimento superior das coisas, a tornou presa fácil da sagacidade da serpente. Dessa forma, Santo Agostinho questiona se isso não seria a razão de, por causa de o homem ter espírito de melhor discernimento, a mulher ter sido usada na suposição de ter entendimento limitado por estar vivendo de acordo com o espírito da carne e não de acordo com o espírito da mente (AUGUSTINE, 1982, XI. 42).

Seguindo nesse arrazoamento acerca da mulher como deficiente do espírito da mente e do homem como excelentemente dotado dessa propriedade, consequentemente mais afinado com o entendimento das coisas de Deus, Santo Agostinho pergunta se não é esta a razão pela qual São Paulo apresenta reserva na atribuição da imagem de Deus à mulher ao dizer, em Coríntios 1. 11: 7, que um homem, na verdade, não deve cobrir a sua cabeça, uma vez que ele é a imagem e glória de Deus, enquanto, ao contrário, a mulher deve fazê-lo, pois é apenas a glória do homem. Entretanto, ainda com aquela relativa simpatia e gentileza de trato com que muitas vezes considera a mulher, Santo Agostinho emenda que isso não quer dizer que a mente da mulher seja incapaz de receber aquela mesma imagem, porque, conforme diz São Paulo em Gálatas 3: 28, nesse agraciamento divino não há diferença entre homem e mulher.

É realmente muito extensa a lista de autores e obras que carregam na Idade Média essa temática da redução da mulher à corporeidade de uma preconceituosa existência material. E toda essa discriminação da natureza e da fisiologia femininas comparecia, na misoginia da Idade Média, 
tendenciosamente associada à visão teológica da mulher. Sobre a questão, R. Howard Bloch comenta que não deixa de haver sempre presente, em todo pensamento misógino da Idade Média, uma metonímica e íntima relação entre o teológico e o ginecológico (1987, p. 20).

São Tomás de Aquino (c. 1225 - 1274), seguindo pegadas tradicionais sobre o assunto, argumenta em Summa Theologiae que, se a mulher é como um macho deformado, ela não deve ter sido produzida no momento da produção original das coisas, porque Deus não poderia ter originalmente criado nada defeituoso ou mau (AQUINAS, 1963, xiii, 1a. 92, art. 1, p. 35-39). Essa visionária sentença do grande auctoritas da escolástica medieval condenaria de vez a mulher a uma indiscutível posição secunda e subordinada ao homem.

Um dos mais frequentes temas a chamar a atenção nos textos medievais foi a lembrança insistente da imagem da mulher responsabilizada pela Queda e pela indução ao Pecado Original. Muito do enfoque e debate sobre o assunto e sobre matérias a ele relacionadas, direta ou indiretamente, evidentemente aconteceu dentro de limites de assunções e pronunciamentos feitos por homens. Uma dessas capciosas assunções, cinicamente irônica, referia-se à já comentada fraqueza natural da mulher, cuja condição de fragilidade quase sempre foi aceita sem contestações. Entretanto, essa aceitação era mais uma das estratégias misóginas para incentivar a fortaleza feminina, a qual seria cinicamente aplaudida ao se revelar enquanto satisfatória das expectativas do homem em relação ao comportamento da mulher. Esta deveria aproximar-se da virtus masculina, prerrogativa do homem. Portanto, a se pensar desse modo figurado, a mulher seria resgatada por meio da sua "masculinização" moral.

Entretanto, foi no seio dessas assunções e pronunciamentos misóginos medievais, forçando barreiras vigorosamente estabelecidas desde longa data, que uma reação contrária, dentre as muitas vozes perdidas de mulheres escritoras medievais, surge cuidando-se indignada de apontar o que diz não compreender acerca das difamações de muitos homens considerados distintos pensadores da cultura.

Assim é que, no contexto da incipiente literatura ocorrida na Idade Média em defesa da mulher, Christine de Pizan (1363 - c. 1430) pode reagir, com seu modo denunciador limitado, apenas a atitudes misóginas próprias da sua época. Faltava-lhe ainda o aprimoramento de uma consciência crítica, temática e retórica próprias sobre a condição feminina verificada na sua ancestralidade e historicidade, num momento ainda não preparado para as transformações necessárias. Isto porque, na marcante extensão da sua obra que trata da denúncia da depreciação 
da mulher, há indícios de que ela ainda estava bastante comprometida com ideais conservadores e latentes relativos ao decoro feminino dela exigidos, fato inegavelmente explicado por ser ela uma mulher que plenamente viveu o seu tempo, desde as recomendações paulinas anteriormente discutidas no início deste estudo.

É nesse sentido que se pode fazer a reflexão crítica de que mesmo a resistência de Christine de Pizan em desconstruir o discurso misógino da sua tradição medieval, ainda assim esse discurso, por não ser construído num vacum, encontra-se naturalmente repleto de inarredáveis condicionamentos misóginos dessa tradição.

Na parte da sua obra que trata da defesa da mulher, pode ser notado que os seus argumentos não são propriamente novos, estando já em circulação por muito tempo, curiosa e suspeitamente, entre homens que escreveram sobre o assunto. Christine de Pizan, na sua reação contra a misoginia, parece ter em mente, sem, entretanto, dar os devidos créditos, o Livre de Leesce (Livro de Leesce), de Jehan Le Fèvre (c. 1320 - 1380), interessada pelas respostas desse livro às alegações misóginas contidas em Les Lamentations de Matheolus (As lamentações de Mateolo), do mesmo autor, ambos escritos na segunda metade do século XIV.

Apesar de se basear em fontes e referências precedentes para a sua apologia e defesa da mulher, a imagem da mulher revista por Christine de Pizan é bastante contundente para a sua época, pois ela demonstrou entender as forças motrizes do pensamento misógino antigo e medieval. Com grande clareza ela acusa a terrível internalização, por parte das mulheres, de uma injustificável desvalorização do seu sexo e da pressuposição do seu limitado intelecto por parte dos homens (PIZAN, 2006, p. 177). Aponta a depreciação hipócrita da realidade feminina por homens arrogados no direto divino de fazê-lo (PIZAN, 2006, p. 123). Suspeita que a misoginia é um tipo de conspiração arquitetada por devassos senis, sustentada por um medo invejoso da potencialidade feminina (PIZAN, 2006, p. 131). Com coragem intelectual, bom senso, abrangência e visão bastante adiantada em termos modernos, Christine de Pizan parece entender que a única maneira possível para um bem sucedido desafio à misoginia implicava em minar a idoneidade de prestigiosas autoridades intelectuais e literárias do mundo clássico, da patrística e da vernaculidade medievais.

Na sua visão defensora da mulher, tem sido argumentado que Christina de Pizan não se coloca suficientemente antitética às discriminações da visão androcêntrica. Entretanto, isso não é totalmente verdadeiro e, para provar o quanto ela desmantela os cânones da misoginia, constrói de 
forma esforçadamente racional, sem abandonar o tom apelativo e emocional preconceituosamente conferido à mulher, a sua obra-bastião em defesa da mulher, dos seus seculares ataques sofridos pela tradicional visão masculinista.

É nesse sentido dialético de construir desconstruindo que Christine de Pizan constrói o polêmico Le Livre de la Cité des Dames (c. 1405) (O livro da cidade das damas), uma espécie de réplica à cidade de Deus que Santo Agostinho havia escrito em contraposição à cidade deste mundo. Portanto, mais do que a ostensiva cidade de Santo Agostinho, a cidade de Christine de Pizan é uma construção defensiva alicerçada na reputação de mulheres, histórica e lendariamente, conspícuas em todo o campo de empreendimento ou moralidade; uma verdadeiramente nova fortaleza para oferecer proteção ao sexo indefeso.

Se Christine de Pizan, por um lado, em seu processo de constituição de uma escrita a contrapelo da misoginia, particularmente em sua Cité des Dames, muito deve à influência de Le Livre de Leesce, de Jehan Le Fèvre, por outro lado, ela se baseia, de forma bastante extensiva em De mulieribus claris (Concerning Famous Women / Famosas mulheres) de Giovanni Boccaccio, primeiramente publicado em 1374.

Nesse sentido, a Cité des Dames é não tão somente um audaz e penetrante questionamento, mas também uma percuciente resposta, baseada na inteligência e no bom senso, a uma vasta quantidade de textos misóginos revisitados. Ainda ofensas contra as mulheres são referidas em relação a passagens da literatura clássica misógina e, inclusive, em referência a passagens da própria Bíblia (PIZAN, 2006, p. 140-146 e passim). Mas Christine de Pizan escolhe diretamente como seu principal perturbador e interlocutor misógino o volumoso Les Lamentations de Matheolus (c. 1371-1372), provavelmente na tradução de Jehan Le Fèvre do poema autobiográfico Liber lamentationum Matheoli (c.1295) (Livro das lamentações de Mateolo), de Mathieu de Bologne. Assim, dada a sólida importância de Les Lamentations de Matheolus como intertexto principal de Christine de Pizan, esse livro será o ponto de partida para a conferição da releitura desconstrutora da misoginia medieval resgatada literariamente pela autora.

Logo no início do Primeiro Livro de Les Lamentations, Christine de Pizan, desprezando a sua autoridade referencial do narrador, indigna-se com filósofos, poetas e oradores depreciadores das mulheres, principalmente na sua malévola conclusão de que todo comportamento feminino é cheio de vícios, concluindo, ironicamente, que Deus só poderia mesmo tê-las criado como vis criaturas deformadas (PIZAN, 2006, p. 119-120). 
Portanto, o primeiro tópico da construção desconstrutora da forma e conteúdo do livro é um axioma fundamental da misoginia, qual seja, o reducionismo essencialista do seu discurso.

Apesar de, nesse ponto, não se referir textualmente às fontes desse tópos da deformidade feminina original, pode-se deduzir que a releitura de Christine de Pizan é de raízes antigas, partindo de uma revisão de postulados da ciência aristotélica a respeito da anatomia e fisiologia do corpo feminino considerado de segunda ordem na dotação da força da vida anímica na geração das espécies quando comparado ao masculino (PIZAN, 2006, p. 86, 103, 130, 154),

Figura 1 - Master of the City of Ladies (fol. from 1400 until 1415), Deutsch: Miniatur aus der "Cité des Dames" der Christine de Pisan.

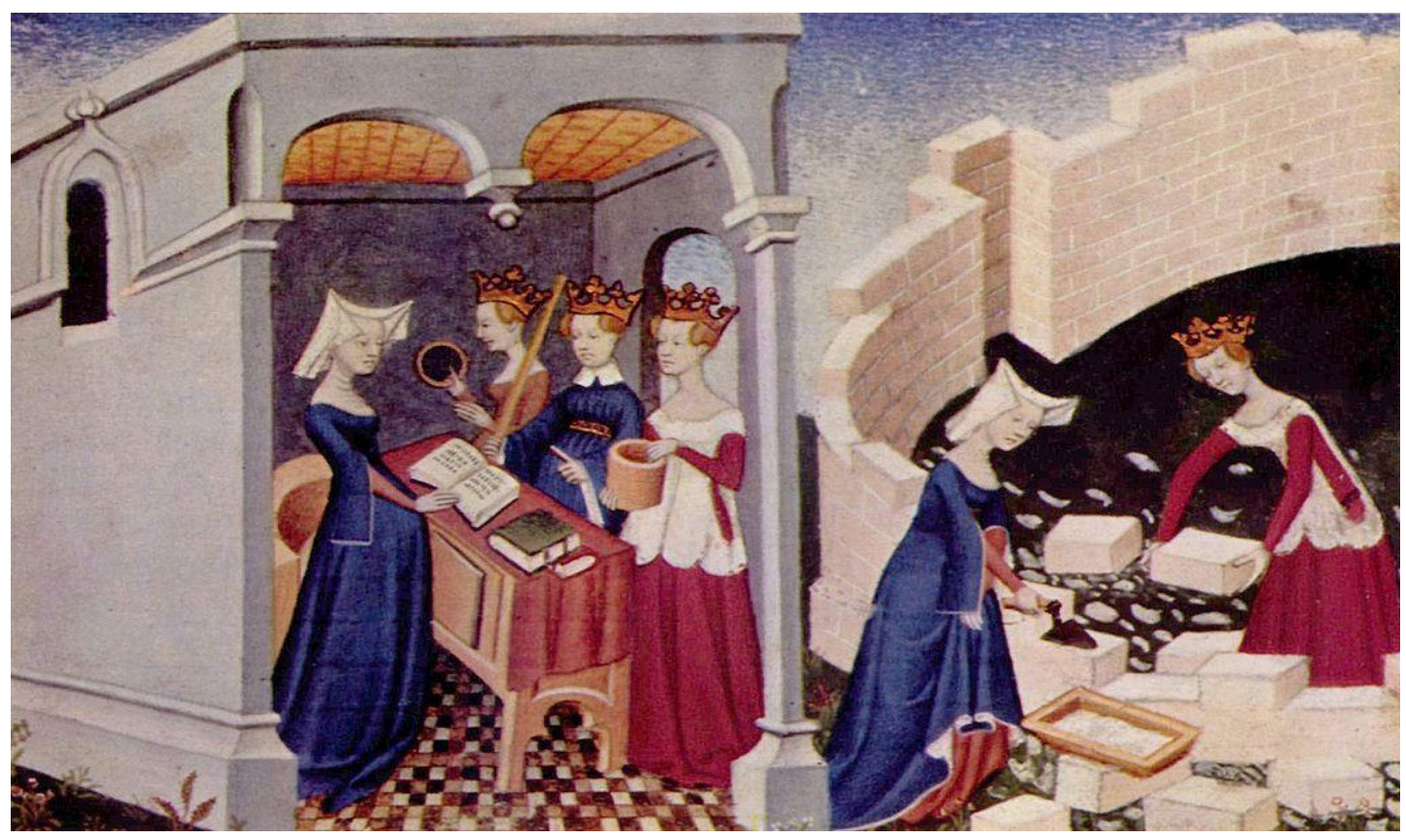

Fonte: Bibliothèque Nationale de France, Fr. 607, fol. 2. Disponível em:

<https://en.wikipedia.org/wiki/The_Book_of_the_City_of_Ladies\#/media/File:Meister_der_'Cit\%C3 \%A9_des_Dames'_002.jpg>. Acesso em: 15 nov 2020.

A partir desse ponto, cheia de pesar por causa dessas constatações, Christine de Pizan recebe a visita de três mulheres soberanas e iluminadas, mais tarde identificadas como Razão, Retidão e Justiça, que vêm acorrer em defesa das mulheres secularmente criticadas no seu sexo. No âmbito do emprego estratégico da ironia como recurso retórico na construção narrativa da cidade das damas de Christine de Pizan, situa-se o fato de as três personagens alegóricas escolhidas como testemunhas de defesa serem do gênero feminino apesar de representarem competências tradicionalmente atribuídas ao masculino. Portanto, assim como o discurso masculinista engendra 
a seu ganho político, o mesmo é feito pelo discurso alegoricamente feminizado das personagens de Christine de Pizan em favor da causa feminina responsáveis por preparar os alicerces da sua cidade com a escavação dos sujos detritos da misoginia.

Nesse sentido, a senhora Razão argumenta, com agudeza silogística, que, mesmo o ataque dos homens às mulheres, com a finalidade de evitar os vícios e a conduta dissoluta delas, não é uma hipótese razoável, porque seria como se condenasse o bom fogo porque queima e a benéfica água porque afoga, já que todas as coisas podem servir tanto para o bem como para o mal (PIZAN, 2006, p. 132). Entretanto, esse percuciente argumento não parece ser inteiramente novo, comprovando o comentário anterior de que Christine de Pizan ainda se apresenta colada aos sistemas da tradição, por vezes numa condição de verdadeira angústia da influência. Já John Gower (c. 1325 - 1408), em um longo poema em oito livros, intitulado Confessio amantis (A Lover's Confession / Confissão de um amante), procurando isentar a mulher da única e imputada culpa na sedução do homem, havia declarado, empregando a mesma metáfora de Christine de Pizan, que “se um homem se dispõe a afogar, e não se refreia, não é culpa da água” (1900, p. 355; tradução minha). ${ }^{3}$

No arrazoamento acerca da necessidade de limpar os detritos sujos da misoginia, além da lembrança de inveterados livros misóginos como a Ars amatoria (2 d. C.) (Arte de amar) e Remedia amoris (Os remédios do amor), de Ovídio (43 a. C. - 18 d.C.) (OVID, 1982, 2001), Christine de Pizan menciona o polêmico e virulento libelo misógino De secretis mulierum (Os segredos das mulheres), um aberrante tratado ginecológico de grande circulação no século XIII, de atribuição espúria a Alberto Magno (1193 - 1206) (LEMAY, 1978, p. 391-400), que denega como corrompedora, na tradição de Santo Isidoro de Sevilha, a menstruação (c. 560 - 636) (1911).

Christine de Pizan mostra-se bastante ressentida pelo fato de o autor de De Secretis Mulieris imputar à Natureza a vergonha por ter produzido o corpo da mulher tão deformado e corrompido por origem. Em resposta a isso, a senhora Razão, na sua usual maneira desconstrutora, faz uso de um dos mais altos pontos de arrazoamento e de aguda engenhosidade jamais visto com tanta propriedade para enaltecer a mulher como a mais nobre criatura do plano divino da Criação. Para tanto, recorda que ela, ao ser formada da costela de Adão, foi a primeira a ser criada no Jardim do Éden, reproduzindo-se aqui o conhecido tópos da costela de Adão (PIZAN, 2006, p. 138-139),

\footnotetext{
${ }^{3}$ No original: "For if a man incites himself to drawn, and will not restrain himself, it is not the water's fault". Revista Graphos, vol. 22, n 3, 2020 | UFPB/PPGL | ISSN 1516-1536
} 
glosado no anônimo Dives and Pauper (1405 - 1410) a respeito do tema da paridade de diretos e reconhecimentos entre o homem e a mulher (1980, p. 66). Aqui, torna-se claramente invertido o pensamento tradicional da supremacia do homem, defendida também pelo misógino Giovanni Boccaccio (1313 - 1373) no livro Il Corbaccio (c. 1355) (The Corbaccio/O Corbacho), escrito apenas a alguns anos antes de Cité des Dames.

A passagem encontra-se repleta de pontos de releitura acerca da visão tradicional da mulher, a começar com a teoria de Aristóteles e de Galeno sobre a imperfeição anatômica e fisiológica do corpo feminino. A insistência de Christine de Pizan na controvérsia teológica da criação da mulher à imagem de Deus, podendo ser rastreada em outras autoridades do calibre de um Santo Agostinho, em De Genesi ad litteram (AUGUSTINE, 1982, p. 175-176), encontrou, entre outros, eco seminal em Graciano, no seu famoso Decretum (c. 1140), um dos livros de referência central da Idade Média por sua compilação do cânone eclesiástico pesadamente fundamentado na patrística (D’ALVERNY, 1977, p. 105-129).

Ainda sobre a argumentação acerca do corpo da mulher como a mais nobre criatura da Criação, outro ponto de releitura de Christine de Pizan consiste na conhecida resposta de autoria anônima Li Bestiaire d'Amour (The Bestiary of Love/O bestiário do amor) de Richard de Fournival, que primorosamente rebate a misoginia de muitos interpretadores da criação de Eva, de autoria anônima (1986, p. 41-43).

Santo Ambrósio parece ser outro ponto dessa releitura, na passagem de De Paradiso que comenta sobre a superioridade do homem em termos de caráter e graça pela dotação da virtude (1896, p. 280). Por outro lado, aquela mesma consideração sobre a excelência originária da mulher também é lembrada por Abelardo (c. 1079 - 1142) na Carta 6, De auctoritate vel dignitate ordinis sanctimonialium) (Sobre a origem das freiras), prazerosamente escrita a pedido de Heloisa já recolhida em votos de reclusão conventual (ABELARD, 1974, p. 129-175).

A seguir, a senhora Razão argumenta, lembrando a piedade e a caridade das mulheres devotas, contra a maledicência daqueles que dizem que as mulheres fazem da própria igreja um local para se exibirem em belos trajes, charmes e sedução (PIZAN, 2006, p. 141), pelo qual as condena Jehan Le Fèvre em Les Lamentations de Matheolus (1892-1905, II. 1107-1242). Ainda nesse sentido derrogatório da mulher, no início do século XIII, um irreverente poema anônimo, intitulado De Coniuge non ducenda (Against Marrying/Contra o casamento) se destaca por falar 
da má esposa que procura distantes abadias de peregrinação para os seus adulterinos propósitos (ANÔNIMO, 1968, p. 81-82).

O mesmo tema constitui ainda legado para discussão de muitas obras misóginas subsequentes, a exemplo do Le Roman de la Rose (The Romance of the Rose/O romance da rosa), de Jean de Meun, que se refere à peregrinação de mulheres de desculpada devoção a lugares santos com intenções luxuriosas (1971, p. 226-237). Seguindo no rol das tradicionais denegações da mulher, Christine aborda o velho provérbio misógino, retomado por Geoffrey Chaucer em The Wife of Bath Prologue (Prólogo da esposa de Bath) (1985, p. 219-239), de que "Deus criou a mulher para chorar, falar e tear" (PIZAN, 2006, p. 142).

Christine de Pizan, talvez com o propósito de desprezar a sujeição da mulher às prendas domésticas, apenas levemente toca na tarefa feminina de tear, bastante recomendada na tradição literária androcêntrica, a exemplo do que faz Marbod de Rennes na sua pretensa defesa da mulher em De matrona (A boa mulher), escrito provavelmente no final do século XII ou início do século seguinte (MARBOD DE RENNES, 1984; FIERO, 1989, p. 110-113).

No tocante a esse trio da domesticidade misógina, a senhora Razão protesta que Maria Madalena ganhou a especial graça de Deus em razão das suas lágrimas, enquanto que o grande pilar da Igreja, Santo Agostinho, havia se convertido pelas lágrimas da sua piedosa mãe (PIZAN, 2006, p. 142-143).

Em referência ao caricaturado vício da incontinência verbal e falastronice feminina criticado pela ala masculina, Christine de Pizan confronta a crítica feita à fala da mulher, reabilitando-a com a menção de que Cristo escolheu uma mulher, Maria Madalena, para anunciar o mistério tão glorioso de sua Ressurreição (PIZAN, 2006, p. 144). Em termos louváveis, Christine de Pizan está a reler aqui a passagem da Carta 6 , de Abelardo, que confere às mulheres, testemunhas do Ressurreto, uma primazia sobre os Apóstolos (1974, p. 129-130) e a passagem, em defesa da mesma causa, de Liber consolationis et consilii (O livro de consolação e conselho), de Albertano de Brescia (c. 1193-?1260) (1873, p. xv-xvii), ambos antecessores seus na defesa da mulher.

Em termos negativos, relê a depreciação da fala feminina, adaptada de Ovídio em Les Lamentations de Matheolus, de Jehan Le Fèvre, que comenta que "poderão antes os pássaros parar de cantar e os grilos no verão do que a mulher achar força para prender a sua língua, não se importando de qual possa ser o dano vindo de suas palavras" (1892-1905, II. 177-250). A força dessa derrogação se dissemina inclusive no melhor da literatura contemporânea a Christine de 
Pizan, a exemplo do famoso poema narrativo da Idade Média inglesa The Vision of Piers Plowman (c. 1360-1387) (A visão de Piers Plowman), de William Langland.

Embora apoiando, de forma conservadora, a lei comum que avalia que a mulher praticar a jurisprudência seria contra a sua verecundia ou modéstia do seu sexo (RAMING, 1976, p. 28), a senhora Razão comenta que as mulheres não têm um intelecto inferior. Pelo contrário, têm sagacidade mental e capacidade criadora e, para exemplificar isso, cita o caso de Nicostrata ou Carmenta, que deu à Itália leis e uma nova língua, isto é, o latim (PIZAN, 2006, p. 192).

No Livro Segundo, a senhora Retidão substitui a senhora Razão, e Christine começa perguntando-lhe se os extremos depreciadores do matrimônio estão certos, citando Valério, o remetente da Dissuasio Valerii ad Ruffinum philosophum nec uxorem ducat (The Letter of Valerius to Ruffinus, against Marriage/A carta de Valério a Rufino, contra o casamento), de Walter Map (1983, p. 287-313), e o próprio São Jerônimo que, em Adversus Jovinianum (Against Jovinian/Contra Joviniano) aconselha a preferência de uma companhia saudável de servos e amigos que a ligação a uma contaminante esposa, que só conduz à distração e ao desespero (JEROME, 1893, p. 412). Ao que a senhora Retidão responde referindo-se a uma verdadeira litania de desgraças sofridas pelas esposas sob o jugo de cruéis e tiranos maridos (PIZAN, 2006, p. 227-228).

Christine de Pizan observa que São Jerônimo - referindo-se a Teofrasto, supostamente um sábio filósofo da Antiguidade (c. 372 - 288), autor de um livro sobre o casamento (Liber de nuptiis) - comenta que casamento e esposa são incompatíveis com a vida do homem estudioso. Ao que a senhora Retidão, dentre uma nobre lista de esposas notáveis, discorre sobre Xantipe, a digníssima consorte de Sócrates, intemerata companheira sua até à morte (PIZAN, 2006, p. 238); perfil extremamente contrário ao feito por São Jerônimo, em seu Adversus Jovinianum, da esposa do filósofo grego (1893, p. 411).

Uma das mais preferidas discriminações da misoginia consistiu na incriminação das mulheres por sua tendência à não preservação da castidade, apenas oferecendo resistência quando o assédio sexual é deveras violento, fato desculpável nos homens (PIZAN, 2006, p. 266-272). Mais uma vez, manifesta-se aqui a costumeira prerrogativa misógina dos critérios duplos, também condenada, entre inúmeras outras fontes, pelo anônimo The Southern Passion (de antes de 1290) [A paixão sulina] (1927, est. 1923).

Essa mesma ambivalência de critérios, o chamado padrão-duplo da maliciosa retórica da misoginia, é discutida, com grande força argumentativa em defesa da mulher, em Dives and 
Pauper, na parte que trata do adultério no homem e na mulher (1980, p. 66-69). O próprio inveterado e cáustico misógino São Jerônimo, contrário aos critérios sexuais duplos na sua Epistula 77, ad Oceanum (Letter 77, to Oceanus/Carta 77, a Oceano), protesta contra a sociedade por consentir aos maridos o que ela censura nas esposas (1983, p. 157-163).

Conclui a senhora Retidão que, a julgar por certos imperadores romanos e dignitários da Igreja, os homens têm muito pouco que se gabar no que se refere ao quesito da constância. Nesse caso, exemplos de extrema perversidade são citados, inclusive na própria História Sagrada, como o de Apóstolo Judas Iscariotes (PIZAN, 2006, p. 275). E, para concluir o tratamento retórico e estilístico, todavia de sutil despontar ideológico em defesa da mulher que lhe fora dada a conhecer no contexto da literatura medieval, Christine de Pizan, no Livro Terceiro de Cité des Dames, coloca a senhora Justiça a identificar as mais nobres ocupantes da sua cidade recém-concluída, estabelecendo a Virgem Maria como sua Imperatriz. Quem vem a ocupar os primeiros postos de destaque são as mulheres bíblicas que, a exemplo de Maria Madalena, permaneceram tão devotas e firmes durante a Paixão de Cristo. A seguir, vêm as santas mártires do cristianismo, detentoras de não menor constância e coragem que aquelas conferidas por Deus aos homens escolhidos. Nesse caso, a senhora Justiça começa com a menção da história da abençoada Santa Catarina da Alexandria que, sacrificada em 307, tornou-se figura pioneira e emblemática do martírio cristão em prol da devoção e da castidade.

Apesar de Christine de Pizan terminar bem sucedida a construção da sua cidade com essa genuína apologia ao feminino irrepreensível, muito do seu discurso desconstrutor ainda constitui, conforme comentado anteriormente, tributo a conservadores e latentes ideais relativos à figura da mulher. Somente com o passar dos tempos, com as transformações da sociedade, é que as nobres e hierárquicas senhoras da Cité des Dames, perderão a sua aura de 'excepcionalidade' da retórica misógina do que Howard Bloch (1995, p. 180-206) chama de capacho-pedestal para figurar a mulher como um paradoxo da perfeição, para dar lugar a indivíduos mulheres que são simplesmente construções históricas e sociais.

\section{Referências}

ABELARD. Letter 6. In: ___ The Letters of Abelard and Heloise. Tradução de C. K. S. Moncrieff. Nova York: Cooper Square Publishers, 1974, p. 129-175. 
ALBERTANO OF BRESCIA. Albertani Brixiensis Liber consolationis et consilii. Editado por Thor Sundby. Londres: [s.n.], 1873.

AMBRose, St. 1961. Hexameron, Paradise, and Cain and Abel. Tradução de J. J. Savage. Nova York: Fathers of the Church, 1961.

AMBROSE, St. De Paradiso. In: Opera. Editado por C. Schenkl. Viena: [s.n.], 1896.

ARISTOTLE. Aristotle: Generation of Animals. Tradução de A. L. Peck. Londres: Heinemann; Cambridge, MA: Harvard University Press, 1963.

AUGUSTINE, St. St Augustine: The Literal Meaning of Genesis (De Genesi ad litteram). Tradução de J. H. Taylor, S. J. Nova York; Ramsey, NJ: Newman Press, 1982.

AUGUSTINE, St. The Trinity. Tradução de S. McKenna. Washington, DC: Catholic University Press of America, 1963.

BEAUVOIR, Simone de. O segundo sexo: mitos e fatos. Tradução de Sérgio Millet. v. 1. Rio de Janeiro: Nova Fronteira, 1980.

BLOCH, R. Howard. Medieval Misogyny. Representations, Berkeley, n. 20, p. 1-24, 1987.

BLOCH, R. Howard. Misoginia medieval e a invenção do amor romântico ocidental.

Tradução de Claudia Moraes. Rio de Janeiro: Edições 34, 1995.

BOCCACCIO, Giovanni. Concerning Famous Women. Tradução de G. A. Guarino. Londres: Allen \& Unwin, 1964.

BOCCACCIO, Giovanni. The Corbaccio. Tradução de A. K. Cassel. Urbana, Chicago; Londres: University of Illinois Press, 1975.

BORRESEN, Kari. Subordination and Equivalence: The Nature and Role of Women in Augustine and Thomas Aquinas. Tradução de C. H. Talbot. Washington, DC: Catholic University Press of America, 1981.

CHAUCER, Geoffrey. The Canterbury Tales. Tradução de D. Wright. Oxford: Oxford University Press, 1985.

D'ALVERNY, Marie-Thérèse. Comment les théologiens et les philosophes voient la femme. Cahiers de civilisation médiévale, Poitiers, n. 20, p. 105-129, 1977.

DIVES and Pauper. Editado por P. Barnum. EETS, 2280, v. I. p. 2. Oxford: Oxford University Press, 1980. 
FIERO, Gloria K.; PFEFFER, Wendy; ALLAIN, Mathé (Eds. e trads.). Three Medieval Views of Women: La Contenance des Fames, Le Bien des Fames, Le Blasme des Fames. New Haven: Yale University Press, 1989.

FONSECA, Pedro Carlos Louzada. Introdução à misoginia medieval de Tertuliano a Chaucer: Estudo e leitura de textos fundamentais. Nova York: Peter Lang, 2020.

FRIEDBERG, Aemilius. Corpus Iuris Canonici, p. 1, Decretum Magistri Gratiani, Austria: University of Graz, 1955.

GALEN. Galen: On the Usefulness of the Parts of the Body. Tradução de M. T. May. Ithaca, NY: Cornell University Press, 1968.

GAWAIN on Marriage: The Textual Tradition of the "De Coniuge non Ducenda". Editado e traduzido por A. G. Rigg. Toronto: Pontifical Institute of Medieval Studies, 1986.

GOWER, John. A Lover's Confession. In: ___ The English Works of John Gower. Editado por G. C. Macaulay. EETS, ES 81, ii. Londres: 1900, p. 354-355.

ISIDORE OF SEVILLE. Isidori Hispalensis Episcopi: Etymologiarum sive originum libri xx, $\mathrm{i}$. Oxford: Oxford University Press, 1911.

JACQUART, Danielle; THOMASSET, Claude. Sexuality and Medicine in the Middle Ages. Tradução de M. Adamson. Cambridge: Polity Press, 1988.

JEAN DE MEUN. The Romance of the Rose by Guillaume de Lorris and Jean de Meun. Tradução de C. Dahlberg. Princeton: Princeton University Press, 1971.

JEROME, St. Letter 77, to Oceanus. In: ___ . The Principal Works of St Jerome. Tradução de W. H. Fremantle. Select Library of Nicene and Post-Nicene Fathers, vi. Oxford: James Parker \& Co.; Nova York: Christian Literature Co., 1893, p. 157-163.

JEROME, St. Against Jovinian. In: . The Principal Works of St Jerome. Tradução de W. H. Fremantle. Select Library of Nicene and Post-Nicene Fathers, vi. Oxford: James Parker \& Co.; Nova York: Christian Literature Co., 1893, p. 346-416.

LANGLAND, William. The Vision of Piers Plowman. Editado por A. V. C. Schmidt. Londres: Dent; New York: Dutton, 1978.

LE FÈVRE, Jehan. Les Lamentations de Matheolus et Le Livre de Leesce de Jehan le Fèvre. Editado por A.-G. Van Hamel. 2 vols. Paris: Bouillon, 1892-1905.

LE GOFF, Jacques. Uma longa Idade Média. Tradução de Marcos de Castro. Rio de Janeiro: Civilização Brasileira, 2008. 
LEMAY, Helen. Some Thirteenth- and Fourteenth-Century Lectures on Female Sexuality. International Journal of Women's Studies, Bridgewater, n. 1, p. 391-400, 1978.

MAP, Walter. The Letter of Valerius to Ruffinus, Against Marriage. In: De Nugis Curialum, Courtiers' Triffles. Editado e traduzido por M. R. James, revisado por C. N. L. Brooke e R. A. B. Mynors. Oxford: Clarendon Press, 1983, p. 287-313.

MARBOD DE RENNES. De matrona. In: . Liber decem capitulorum. Editado por R. Leotta. Roma: Herder, 1984.

OVID. Ars amatoria. In: Ovid: The Erotic Poems. Tradução de Green. Harmondsworth: Penguin, 1982.

OVID. The Cures for Love. Tradução de A. S. Kline, 2001. Disponível em: <http://www.poetryintranslation.com/PITBR/Latin/CuresforLove.php>. Acesso em: 19 maio 2020.

PIZAN, Christine de. A cidade das damas. Tradução de L. E. de F. Calado. In: CALADO, Luciana Eleonora de Freitas. A cidade das damas: a construção da memória feminina no imaginário utópico de Christine de Pizan / Estudo e tradução. 2006. 368p. Tese de Doutorado Universidade Federal de Pernambuco. Disponível em:

<http://www.dominiopublico.gov.br/download/texto/cp059489.pdf>. Acesso em: 05 jan. 2011.

PIZAN, Christine de. The Book of the City of Ladies. Tradução de E. J. Richards. Nova York: Persea Books, 1982.

RAMING, Ida. The Exclusion of Women from Priesthood ...: A Historical Investigation of the Juridical and Doctrinal Foundations. Tradução de N. R. Adams. Metuchen, NJ: Scarecrow Press, 1976.

RICHARD DE FOURNIVAL. Response to The Bestiary of Love. In: Richard's Bestiary of Love and Response. Tradução de J. Beer. Berkeley. Los Angeles; Londres: University of California Press, 1986, p. 41-43.

SOUTHERN passion, (the). Editado por B. D. Brown. EETS, os 169. Londres: Oxford University Press, 1927.

TERTULLIAN. The Apparel of Women. In: __ Tertulian: Disciplinary, Moral and Ascetical Works. Tradução de E. J. Daly e E. A. Quain. Nova York: Fathers of the Church, 1959.

Recebido em: 22/09/2020

Aceito para publicação em: 14/11/2020 